\title{
Chapter 7 \\ Conclusions: Towards Entrepreneurial Education Through the Change Laboratory
}

\begin{abstract}
This conclusive chapter argues that the Change Laboratory intervention has an impact on the teaching staff, the students and the organisation, the role of the management being key in sustaining the change effort. A Change Laboratory intervention develops initiative and entrepreneurship in the teaching staff, both through its outcomes and during the formative process itself. Firstly, the outcome of Change Laboratory can be a new concept, and its implementation brings a renewal of pedagogy. The eventual result is to integrate entrepreneurship into the core of the school, as this change in teaching practice creates value. Second, the process of participation in the Change Laboratory causes the development of the teaching staff's collective transformative agency, changing the focus of discourse from criticising the state of things and blaming others, to committing to implement a coordinated multidisciplinary project with new didactics. The participation process has also caused a switch from individual to collective actions. The Change Laboratory, therefore, demonstrates that entrepreneurship becomes a collective and social phenomenon where individuals face a problem that threatens their community. They take the lead and find a solution that creates value for themselves and their community. With the Change Laboratory for teachers in-service training, new ideas of pedagogical practices are transformed into collective action and value. This view of entrepreneurship emphasises the dimension of the sense of initiative and entrepreneurship as key competence for participation, citizenship and personal fulfilment, which provide the foundations for a New Skills Agenda.
\end{abstract}

Keywords Entrepreneurial education - Change Laboratory - Teacher training Collective transformative agency $\cdot$ Interdisciplinary project

Sense of initiative and entrepreneurship

This chapter seeks to answer to the research question formulated in Chap. 1, and it is divided in four sections. While the first section summarises the content of the previous chapters, the second looks at the impact of the Change Laboratory. This goal is achieved by analysing the figures of pre-enrolments from 2015 to 2018, and by reviewing the changes that took place in the teaching staff, in the programme and in the institution. The impact on the teaching staff, the focus of this Change Laboratory 
intervention, is analysed by looking at the changes in the five characteristics of the SIE interview described in Chap. 2. The impact on the programme and therefore on students is visible in the new didactics, a competence approach preparing teachers more effectively for work and giving them more participation in terms of decisionmaking. The leadership was structured to support the teachers' sense of initiative and entrepreneurship.

The third section seeks to answer to the research question put forward in Chap. 1. This research explores the extent to which a Change Laboratory intervention as inservice training can be useful for promoting a sense of initiative and entrepreneurship among the teaching staff. This part of the chapter argues that the Change Laboratory develops the teaching staff's sense of initiative and entrepreneurship in the outcome and in the process. The outcome of a Change Laboratory can be a new concept for their collective activity, and the implementation of the new concept leads to a pedagogical renewal in the teaching practices. Through a interdisciplinary project, this Change Laboratory intervention ensured a switch towards a competence-based approach to teach surveying. This transformation created value for the school, the creation of value being a core element for entrepreneurship. The impact on the process can be found in the participants' development of a collective transformative agency, from criticising and blaming to commitment and implementation of the new concept. While a top-down approach determines resistance in teachers who become the executors of policy recommendations, bottom-up approaches, especially formative interventions, are designed to help develop and express collective transformative agency-with the participants tackling important issues that can only be solved by a cooperative action. The fourth section draws final conclusions. With the shift of the unit of analysis from the individual to a collective activity system, the Change Laboratory sheds new light on entrepreneurial education for a new skills Agenda.

\subsection{The Story so Far}

Skills, a term used to indicate what an individual can do, understand and know, are a path to prosperity and employability. Within the 'A new Skills Agenda for Europe', the European Commission (2016) has launched a revision of key competences, and special interest will be given to the promotion of entrepreneurial and innovation-oriented mindsets. In the literature, there is a polysemy around the term entrepreneurship education. Consistent with the literature (Lackeus, 2015), in this study entrepreneurial education is the general term embedding the others (such as enterprise and entrepreneurship education), and a sense of initiative and entrepreneurship is a European key competence for lifelong learning. It deals with turning ideas into action (European Commission, 2007), and it represents the outcome for entrepreneurial education.

When designing and delivering a course in entrepreneurial education, there should be a coherence between the learning outcomes, the activities of teaching and learning and the assessment practices (QAA, 2018). Assessment is defined as an educational practice serving to fill the gap between the desired outcomes and what the student has achieved. Not only assessment is essential to promote learning in students, but it also 
allows teachers to reflect on and enhance their programmes (Biggs \& Tang, 2011). Drawing on both literatures of key competencies and entrepreneurship education and training, the assessment of a sense of initiative and entrepreneurship cannot be a 'one size fits all' process, but should be a programme tailored to the requirements of the institution and the environment, with the active collaboration of the stakeholders. In the case of teacher evaluation, the Sense of Initiative and Entrepreneurship questionnaire seeks to measure how secondary teachers educate for the key competence of the sense of initiative and entrepreneurship as cross-curricular subject (Morselli, 2017). Any teacher could, therefore, educate for a sense of initiative and entrepreneurship while teaching their subject. One possible way to implement this strategy is by teachers role modelling for students what entrepreneurship looks like in their teaching practice (European Commission, 2014; Penaluna, Penaluna, Usei, \& Griffiths, 2015). The Sense of Initiative and Entrepreneurship questionnaire was administered to the teachers and workshop assistants who later participated in the Change Laboratory. Results suggested that the teaching staff would need help to gain a sense of initiative and entrepreneurship to cross the boundaries between disciplines, the boundaries between school and work, as well as apply active didactics coupled with diverse forms of assessment.

A theory of entrepreneurship calls for a theory of learning, and most of the literature on entrepreneurship relies on Kolb's (1984) theory of experiential learning. This theory has issues, for example it was initially developed as an inventory, and it is based on a cycle that is not theoretically grounded (Morselli, Costa, \& Margiotta, 2014). Another theory of adult learning is necessary to back entrepreneurship, and this can be expansive learning, a theory of innovation and collective change of practices where practitioners learn something that is not yet there (Engeström, 2015). The unit of analysis includes a collective activity system mediated by artefacts and oriented to an object; such system is studied in its network of relationships with the other activity systems (Engeström, 2001). An activity system is characterised by a community of individuals with diverse points of view. Yet to understand its present form and its possibilities, a historical perspective is essential, since within this lens contradictions can be recognised, such as the accumulated structural tensions within and between activity systems. These elements play a key role in expansive transformation of the activity system itself. A school course can be studied as an activity system, the object being the students' learning. Formative interventions, especially the Change Laboratory, are designed to trigger cycles of expansive learning, and are based on two principles, 'double stimulation' and 'ascending from the abstract to the concrete' (Sannino, Engeström, \& Lemos, 2016). The Change Laboratory is suited for activity systems facing a major challenge; it is characterised by a highly mediating setting with writing surfaces used according to different levels of abstraction and to an historical perspective (Virkkunen \& Newnham, 2013). Other important features of the Change Laboratory are a dialectical movement between distanced intellectual analysis and close emotional involvement, and the mirrors, videotaped materials gathered on the field useful to trigger discussion.

A course in surveying in an Italian secondary technical institute was chosen for the research because it had suffered from a dramatic loss of students in recent years. 
7. Consolidating the new practice:

Multidisciplinary project in school year 2017/2018.

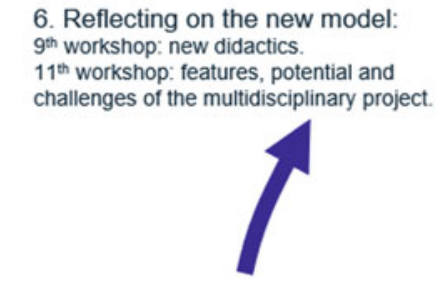

5. Implementing the new model: Multidisciplinary project in school year 2016/2017.

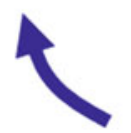

4. Examining the new model: $8^{\text {th }}$ workshop: the department council approves the multidisciplinary project.
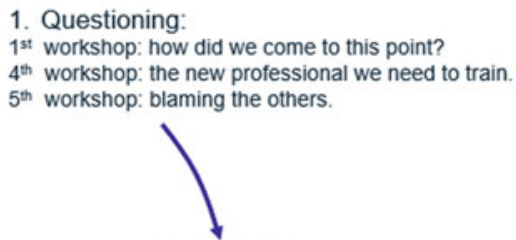

1. Analysis:

$2^{\text {nd }}$ and $3^{\text {rd }}$ workshop: effects of the school reform and the change of the school principal.

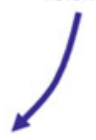

3. Modeling the new solution: $6^{\text {th }}$ and $7^{\text {th }}$ workshop: multidisciplinary project around technical subjects with a leading role of the workshop assistants.

Fig. 7.1 Expansive learning process during and after the Change Laboratory intervention

Moreover, the teaching staff had not fully understood the changes in surveying that had taken place with the school reform and after almost 10 years were still training for the pre-reform surveyor, with a curriculum centred on the construction of new buildings. Instead, the school reform and the market transformations had called for a switch from the construction of new to the renovation of the old, the green skills and the management of the territory. The new concept developed during the Change Laboratory workshops is that in the two Grade 5 classes, 3 technical teachers for each class would teach around a common and realistic interdisciplinary project concerning the construction of a new building in an area close to the school. The realistic and hands-on interdisciplinary project would be carried out around traditional technical topics, allowing students to make connections and understand deeply the core concepts of surveying. It was intended to be coordinated by the workshop assistants who liaise the subjects.

Figure 7.1 summarises the expansive learning triggered by the Change Laboratory intervention. Under each expansive learning action, there is the workshop where it was dealt with and the outcome. The expansive learning process continues outside the 11 Change Laboratory workshops with the implementation of the interdisciplinary project in school year 2016/2017 (5th action) and its consolidation in $2017 / 2018$ (7th action).

Described in the words of the participants - teachers, students and workshop assistants - the new concept has features, potential and challenges, but has also historical antecedents. The senior teachers implemented a similar project when it was a mandatory activity carried out during specifically allocated hours before the school reform. However, a new professional figure, the workshop assistant, now helps connect the diverse subjects into a whole. Additionally, the project requires a competence-based approach and students' group work. These elements distinguish the interdisciplinary project from the projects carried out at the end of the 1990s. According to the teach- 
ers, the project features are that it is based on realistic tasks and problems, it connects diverse technical subject matters and allows students to work in groups. The interdisciplinary project also has diverse transformative potentials: it can change the state exam based on a competence; it calls for an evaluation system beyond knowledge towards competence; it can change the curriculum to make it more up to date; through its advertisement on the school open day it has the potential to attract enrolments; and through group work it fights bullying and promotes group work as an important skill set for working life. The interdisciplinary project also faces challenges: it is more multidisciplinary than interdisciplinary; the role of workshop assistants is not fully utilised because of the high turnover and lack of experience; and it could result in an excessive workload for students.

The findings of this analysis were used as a starting point during the third followup. From one perspective, this workshop served for validating the research findings. From another perspective, the tasks served to trigger the expansive learning action of reflecting on and evaluating the process, to think what else needed to be learnt for the better implementation of the interdisciplinary the following school year. The participants in the follow-up workshop-teachers, workshop assistants and students-confirm they now see the interdisciplinary project as based on group work, real tasks, and connecting the technical disciplines. This development demonstrates a move from a knowledge-based approach to competence-based approach, as well as giving a holistic perspective of surveying. A drawback concerns the workshop assistants whose connecting role is underestimated. Given the importance that the participants attribute to teaching the interdisciplinary project according to a competence-based approach, the second task of the follow-up was to, with grids, evaluate the extent with which the interdisciplinary project had been delivered according to a competencebased approach. Compared with the students' point of view, the teachers tended to overestimate the degree they teach the interdisciplinary through a competence-based approach.

In CHAT terms such tension between teaching for knowledge and teaching for competence is a manifestation of a tertiary contradiction. New forms of activity develop through the resolution of contradictions, and in tertiary contradictions, the implementation of the new model causes tensions between the present form and the application of the new model in the elements of the activity system (Virkkunen $\&$ Newnham, 2013). In this research, the application of the interdisciplinary project provokes a tertiary contradiction which is visible: in the tensions between the old and the new objects, with a curriculum delivered, respectively, according to a knowledgebased and a competence-based approach; in the tensions between the old and new division of labour (which is a significant factor in coordination between teachers, as well as between teachers and workshop assistants); and in the tensions between the old and new rules (for example in the old and new didactics, respectively, students in the class working alone or in groups). The resolution of this contradiction will allow the advancement through the expansive learning process with a interdisciplinary approach delivered according to a fully competence-based approach. 


\subsection{Impact of the Change Laboratory Workshops}

This section deals with the impact of the workshops on the student enrolments, the teaching staff, the students already in the school, and the organisation. The European Commission (2014) defines impact as observable changes at different levels (individual, organisational, societal) as a direct consequence of an educational activity. The observable changes can be qualitative or qualitative. Concerning quantity, this Change Laboratory was set to help the teaching staff tackle the diminished number of enrolments. Table 7.1 shows the pre-enrolments in surveying from the school year 2015-2016 to 2017-2018, two years the interdisciplinary project has been running.

In the Italian school system pre-enrolments are a better indicator than the actual enrolments, because they allow for a more effective appraisal of a school's attractiveness to future students. Enrolments also include the students who failed Grade 1 and simply repeated it, and this figure can vary. The pre-enrolments of the school year 2015-2016 correspond to the school year when the Change Laboratory was held. However, follow-up workshops were held regularly to sustain the expansive learning process. Overall, the number of students in surveying has been growing since the Change Laboratory workshops. During the Change laboratory, the participants discussed how to better promote surveying outside the school, for example with better organised open days. The interdisciplinary project could be used to promote the course as a unique opportunity featured at the school during both open days and through the students' word of mouth about their experiences. Beyond improvement of freshmen, however, there have been qualitative changes in the way teachers educate for a sense of initiative and entrepreneurship, in the students' achievement of outcomes with changes in the curriculum, as well as at the organisational level.

Firstly, the five dimensions of the SIE interview on the entrepreneurial teacher described in the second chapter can help show the impact of the Change Laboratory on the teaching staff. The first characteristic of entrepreneurial educators is that they embed into their course a selection of learning outcomes of the sense of initiative and entrepreneurship and make use of an appropriate mix of assessment forms, and teachers have not yet moved in this direction. The second feature, however, is a focus on active pedagogies, and the design teachers, a major subject in surveying, have extensively made use of group work and project-based work to deliver their courses, even though with the tensions mentioned in the previous chapter. The third characteristic is educating for entrepreneurial attitudes, and during the Change Laboratory the teachers have repeatedly discussed the student's attitudes, especially initiative and autonomy, and how to educate for them. There is an increasing awareness that they should educate for the entrepreneurial attitudes that are important for the surveyor. The fourth characteristic is to connect across the boundaries between disciplines within the school, as well as those between the school and the outside world. While

Table 7.1 Pre-enrolments in the school before and after the Change Laboratory intervention

\begin{tabular}{l|l}
\hline School year/course & Surveying \\
\hline $2015-2016$ & 27 \\
\hline $2016-2017$ & 32 \\
\hline $2017-2018$ & 29 \\
\hline $2018-2019$ & 37 \\
\hline
\end{tabular}


to some extent the teaching staff already crossed the boundaries between school and the outside world with school visits and surveying in the field, the major contribution of the interdisciplinary project is that they started crossing the boundaries between their disciplines by organising a interdisciplinary project that was coordinated by the workshop assistants. The fifth feature of the entrepreneurial teacher is to be entrepreneurial in a lifelong learning perspective, both inside and outside the school environments and throughout their professional development. Rather than being a specific course on entrepreneurship education, the Change Laboratory sought to develop the teachers' collective sense of initiative and entrepreneurship. Due to an increased awareness of the importance of school open days which was discussed during the Change Laboratory, surveying teachers and their workshop assistants are also taking better care in how their course is presented during the open days. They also advertise their interdisciplinary project as flagship initiative. Before the Change Laboratory, the teaching staff was blaming other factors for the drop in the enrolments the course had suffered from. After it had taken place, the surveying teaching staff has taken the lead to change its circumstances. Such increased sense of initiative and entrepreneurship is the most important outcome of the Change Laboratory intervention and will be further discussed in the following section.

Concerning the impact of the Change Laboratory on students, this development can be seen in terms of new didactics, in a curriculum delivered according to a competence-based approach, and in their increased participation in the decisionmaking processes. One of the effects of the interdisciplinary project has been a switch from lectures to active didactics such as group work, which is recognised as one the outcomes for entrepreneurship education (Bacigalupo, Kampylis, Punie, $\&$ Brande, 2016). Students have known more about cooperation and rules to make a group work effective and have acquired more autonomy. This conclusion is in line with Haara and Jenssen (2016), who contend that pedagogical entrepreneurship should move beyond business creation towards human development with an emphasis on authentic activities, action and self-regulation. For Draycott and Rae (2011), enterprise education can be simply considered a way of solving the long-standing gap between education and the work of work, and this area has been the objective of the interdisciplinary project. This study shows how students learnt through entrepreneurship rather than about entrepreneurship.

Another observable change in students caused by the Change Laboratory has been an increased participation in the process of decision-making. Through in-class focus groups with teachers, discussions and participation in the follow-up workshop, students have made their voice heard on the potentials and threats of the interdisciplinary project, but also on the didactics such as group work. This is in line with Dal, Elo, Leffler, Svedberg, and Westerberg (2016), who suggest that pedagogical entrepreneurship is useful to develop new and emancipatory pedagogies which lie in contrast to more strict approaches to learning and teaching.

Concerning the impact of the Change Laboratory at the organisational level, I interviewed the school director asking for the changes she could observe, and she pointed out three types of effects. Firstly, teachers have gotten far more active in promoting their courses during the school open days. The result has been an improvement in pre-enrolments not only in surveying, but also in the other courses. Second, the 
school director perceived an improvement of the image of the school outside. This has been communicated by privileged observers, institutions and journalists with sentences such as "We know your school goes above and beyond" or "In delivering work experience you are the best". Third, the school director reports an increased sense of initiative and entrepreneurship from the teaching staff. It was the surveying teachers who autonomously implemented the interdisciplinary project. Now the school's young teaching staff turn to her with more trust and the will to cooperate, a condition for pedagogical entrepreneurship (Ruskovaara, Hämäläinen, \& Pihkala, Ruskovaara et al. 2016), and before the Change Laboratory the situation was quite different.

At the organisational level the CL has left a mark on the course of surveying, which has started acting with a sense of initiative and entrepreneurship: to promote it and to improve it. Before the Change Laboratory, the teaching staff was blaming the others (the school director, the course in graphics, the students and parents, etcetera) for the drop in the enrolments the course had suffered from. After the Change Laboratory, the surveying teaching staff has taken the lead to change their course's circumstances. The role of the school management has been to create the conditions for the teaching staff to take initiatives to revitalise their course in surveying; the issue was how to call surveying teachers and workshop assistants for action. In this Change Laboratory process, the role of school management, especially the vice director and the school director, has been of help and interest. From one perspective, the vice director took part to each workshop and was determined to set the method to develop the new concept. He came with a written idea of interdisciplinary project, and he proposed to start discussing it to find the best concrete solution possible. From another perspective, the school director promoted the research with the organisation of the launch events in the school. It was she who suggested that the surveying course could receive most benefit from the formative intervention. However, although she was kept informed on the outcomes of the workshops, she never made pressures on the participants allowing an autonomy among her staff in the end, even when some of the participants (in the historical analysis) criticised her for having chosen in 2010 to run new courses in the school. When the participants had conceived the new idea, she participated in the workshop to help implement the interdisciplinary project according to the school regulations and the available resources. Coherently with formative interventions where it is the participants who take the lead (Engeström, 2011), the task of the management has not been to tell the teachers what they could do, but support them in their change effort which was led by them. This approach encouraged characteristic attitudes of entrepreneurial education such as autonomy, risk-taking and experimentation.

\subsection{A Double View of Entrepreneurial Education in the Process and in the Outcome}

This research sought to explore the extent which a Change Laboratory intervention as in-service training can be useful for promoting a sense of initiative and entrepreneurship among the teaching staff. The research question was: 
"To what extent can a Change Laboratory help the teaching staff turn ideas into actions?" (RQ1).

The expression "to turn ideas into action" represents the definition of a sense of initiative and entrepreneurship as from the European Commission (2007). It is maintained that by showing a sense of initiative and entrepreneurship in the school, the teaching staff will act as role model for their students, as argued extensively in the literature (European Commission, 2014; Heinonen \& Poikkijoki, 2006; Penaluna et al., 2015; Ruskovaara \& Pihkala, 2015).

Following the analysis of the section on the impact above, this chapter argues that the Change Laboratory has a double effect on the teachers' sense of initiative and entrepreneurship, in the outcomes and the process.

- The outcome of a Change Laboratory can be a new object and concept for their collective activity (Engeström \& Sannino, 2010). In this research, the new concept has been a interdisciplinary project. The consequence in this case was a pedagogical renewal in the teaching practices: competence-based approaches with structured group work and assessment forms, with a central role of workshop assistants. As it has been displayed in the impact of the research above, the new concept has undoubtedly created value for the organisation and the students, and value creation-which can be either economic, social and cultural-represents the common core of entrepreneurship and the goal for entrepreneurial education (Lackeus, 2015). Furthermore, Peltonen (2015) analysed the pedagogical side of entrepreneurship and argued that teachers see entrepreneurial education as resulting in pedagogical renewal and professional development. In this study, the Change laboratory has brought pedagogical renewal with the teaching of a interdisciplinary project, which carried the need for their professional development towards a competence-based approach to teaching. Hence, rather than becoming the recipients of linear interventions and policy recommendations, with the Change Laboratory the teaching staff collectively chose what they thought they should learn to innovate their practices.

- The second way with which the teaching staff have developed a sense of initiative and entrepreneurship stems from the process. The participation in the Change Laboratory allows for the emergence and development of collective transformative agency, which is defined as "breaking away from the given frame of action and take the initiative to transform it" (Virkkunen, 2006, p. 49). Throughout the workshops, the participants shifted from criticising the state of things, to blaming others, to committing to teach a coordinated interdisciplinary project with new didactics. Simultaneously, they moved from individual to collective initiatives. Before the intervention they taught their subject, as it was separate from the other subjects in the school, and they complained about the lack of cooperation. In order to implement the new concept, the teaching staff had to work collectively to incorporate a common topic within the context of their classroom.

It can, thus, be concluded that with the Change Laboratory for teachers in-service training, new ideas of pedagogical practices are transformed into collective action and value. This definition embeds the double effect of the Change Laboratory in creating the conditions for the development of the teachers' sense of initiative and 
entrepreneurship. That is, in the product with the implementation of new pedagogical practices that create value for the school, and in the process with the development of their collective transformative agency. Opposed to linear interventions, formative interventions set the stage for the participants to take the lead of the learning process. Since teachers are also citizens, they must learn and display these competencies for both themselves and their students (Gordon et al., 2009), and this approach is made possible through the Change Laboratory intervention. Similar to the students, the teaching staff learnt through entrepreneurship rather than about entrepreneurship (Haara and Jenssen, 2016).

One of the curiosities of this study has been on how to document the outcomes of the Change Laboratory in the process that is the teaching staff's collective transformative agency. In the Change Laboratory, the consequential actions of change are mostly performed in vivo, after and between the workshops (Engeström, 2011). Agentive actions do not stand on their own, but can only be studied as contextualised in their activity system, while the individuals break away from the given frame of action and implement the new practices. Hence, the solution on how to make visible the participants' development of transformative agency was to show how the interdisciplinary project was conceived, how it breaks away from the old and it is being developed. It is the actions taken to overcome contradictions that materialise the teaching staff's collective transformative agency. By showing how a new object is generated and how participants strive for its progressive implementation, this study shows the participants' collective transformative agency. Translated into an educational language, it could be said that by showing how an idea is being generated and collectively turned into action, this study shows the development of the participants' sense of initiative and entrepreneurship.

There are, however, differences between a collective transformative agency in CHAT and a sense of initiative and entrepreneurship. The two terms come from different ontologies, and therefore should not be confused. Collective transformative agency stems from Vygotksian studies, while a sense of initiative and entrepreneurship was conceived within European educational policies. In an activity system, a collective transformative agency focuses on how the participants collectively break away from the given frame of action. In the case of a sense of initiative and entrepreneurship, the focus is on how innovative ideas are transformed into courses of action by the individual, thus creating value. Hence, a collective transformative agency focuses on the collective contribution of all individuals to their object, while a sense of initiative and entrepreneurship concentrates on the individual. Although it is the individual who displays and owns a sense of initiative and entrepreneurship, this attitude can also be collectively displayed during coordinated actions.

Learning a sense of initiative and entrepreneurship in the process and in the outcome is closely related to the two key processes of the Change Laboratory, double stimulation and concept formation. While Chap. 4 shows the chain of stimuli used for double stimulation in the workshops that develop in the participants a collective transformative agency, Chaps. 5 and 6 detail what the interdisciplinary project is like. Appendix A shows the interdisciplinary project as it was in April 2016, a twopage document entirely written by the participants with the description of contents, 
didactics and actors involved. While these chapters give an instantaneous picture of what the interdisciplinary project is like in the specific historical movement, during the implementation the new concept is constantly evolving and being improved. During the school year 2017-2018, for example, the teaching staff selected a different area with a different project to be designed, a gas station. They also changed the way student group work was carried out in the class with smaller groups, and better coordinated their subjects and the role of the workshop assistants.

\subsection{Concluding Remarks. Towards Teacher Training in Entrepreneurship with the Change Laboratory}

Agency is a relevant mediator of educational change (Kumpulainen, Kajamaa, \& Rajala, 2018). Change Laboratory are advisable when organisations are facing major transformations, and nobody knows what needs to be learnt (Engestrom \& Sannino, 2010). The Change Laboratory is characterised as a bottom-up approach, where the change effort is initiated and led by the participants, with the participants tackling issues key for the organisation and that can only be solved by a cooperative effort. It should also be considered that, as they are remediating environments, Change Laboratory workshops are open-ended processes, and the outcomes cannot be determined at the beginning. An example is that the teachers set into use the concept of competence instead of entrepreneurship, but this should not be seen at odds with the aim of this study. Firstly, formative interventions are guided and led by the participants, therefore the researcher's task is to facilitate the change effort rather than imposing their agenda or own concepts. Second, although the participants admitted during the workshops that they had been forced by the school reforms to move to competence in their curricula without never being trained on competence-based education, this concept was much more familiar than entrepreneurship. Third, as I noted in Chap. 1, the model of Sturing, Biemans, Mulder, and De Bruijn (2011), which was used in the eleventh workshop, has extraordinary similarities with pedagogical entrepreneurship. It is centred on authentic projects that are inspired by 'in the world out there', cooperation among teachers and lifelong learning skills such as reflection and citizenship.

As a new concept, the interdisciplinary project has been a way to transcend the dialectics between old and new pedagogies. Likewise, learning environments and other concepts introduced in education (Engeström, 2009), competence could become a static generalisation of little use if not contextualised appropriately. Rather than teaching for competence for the sake of doing so, the Change Laboratory workshops allowed the teaching staff to fill this concept with meaning and to make it relevant for their context.

This research has been characterised by a double thread: the tensions between formative and linear interventions, and the tensions between policy documents on entrepreneurship and how entrepreneurship is actually enacted and taught by educators. Concerning the first tension between formative and linear interventions, this study explains their possible circular relationship: best practices lead to emerging practices, which in turn can become best practices. The SIE interview displays the strengths and weaknesses of teachers that can be tackled through a formative interven- 
tion. During the Change Laboratory, the teachers designed a interdisciplinary project which was implemented the following school year in 2016/2017, and an improved version was delivered in 2017/2018, thus becoming a flagship in the school. This suggests a possible circularity between linear interventions-producing best practices, and formative interventions-producing emerging practices that later become best practices. Regarding the second thread on the tensions between the concept of entrepreneurship education as it is described in policy documents and how it is conceived and implemented by educators, this research suggests that the teaching staff can teach through entrepreneurship, that is by being entrepreneurial and change the course programme embedding pedagogical entrepreneurship, without necessarily knowing about entrepreneurship.

This study concentrated on understanding the interdisciplinary project and tracing the expansive learning cycle that led to the development of a new activity system. However, the data gathered in this research can be a springboard for future research such as understanding the development of agency both through double stimulation and relational agency:

- applying the model of Double Stimulation put forward by Sannino (2016) to the Change Laboratory workshops to analyse how the first stimuli and conflict of stimuli trigger auxiliary motives and volition;

- apply the concept of relation agency elaborated by Edwards (2011) to the workshops to study the way the participants cooperate to expand the object of their activity, how they recognise the motives and resources of the colleagues as they interpret the object, and align own responses to the improved interpretations;

- studying the principle of ascending from the abstract to the concrete, that is how a germ cell is developed into a fully operating concept (Sannino \& Engeström, 2017);

- analysing the power relationships within the workshops (Ravitch \& Carl, 2015).

With the shift of the unit of analysis from the individual to a collective activity system, the Change Laboratory sheds new light on entrepreneurial education. Entrepreneurship is not only an individualistic and economic phenomenon (Jones \& Spicer, 2009; Kyro, 2006), and becomes a collective and social phenomenon where individuals face a problem that threatens their community. They take the lead of the situation and find a solution that creates value for themselves and their community. Notwithstanding the creation of value, entrepreneurship moves from business creation to tackling societal needs. In a similar vein, Bahri and Haftendorn (2006) suggested that the success of entrepreneurial education could indeed be measured by contributions to learning, to teaching practice, to poverty reduction and community improvement, and to more collective decision-making. This view of entrepreneurship encompasses the opposition between entrepreneurship as the lonely entrepreneur and intrapreneurship as employees being entrepreneurial within companies. In one sense, the division between these perspectives is because change does not start from an individual hero but is carried out by a collectiveness, with the activity system as unit of analysis. Notably, the management and the practitioners are not seen in opposition, but they rather cooperate to make change happen in a bottom-up change effort. 
This view of entrepreneurship emphasises the dimension of the sense of initiative and entrepreneurship as key competence for participation, citizenship and personal fulfilment, for a new skills agenda in Europe.

\section{Bibliography}

Bacigalupo, M., Kampylis, P., Punie, Y., \& Brande, G. V. D. (2016). EntreComp: The entrepreneurship competence framework. Brussels: Publication Office of the European Union.

Bahri, S., \& Haftendorn, K. (2006). Towards an Entrepreneurial Culture for the Twenty-first Century: Stimulating Entrepreneurial Spirit through Entrepreneurship Education in Secondary School. Paris: UNESCO Publishing.

Biggs, J., \& Tang, C. (2011). Teaching for quality learning at university. What the student does. New York: McGraw-Hill.

Dal, M., Elo, J., Leffler, E., Svedberg, G., \& Westerberg, M. (2016). Research on pedagogical entrepreneurship-a literature review based on studies from Finland Iceland and Sweden. Education Inquiry, 7(2), 30036.

Draycott, M. C., \& Rae, D. (2011). Enterprise education in schools and the role of competency frameworks. International Journal of Entrepreneurial Behavior \& Research, 17(2), 127-145.

Edwards, A. (2011). Building common knowledge at the boundaries between professional practices: Relational agency and relational expertise in systems of distributed expertise. International Journal of Educational Research, 50(1), 33-39.

Engeström, Y. (2001). Activity theory as a framework for the study of organizational transformations. Knowing in practice, February, 2001, University of Trento, Italy.

Engeström, Y. (2009). From learning environments and implementation to activity systems and expansive learning.

Engeström, Y. (2011). From design experiments to formative interventions. Theory \& Psychology, 21(5), 598-628.

Engeström, Y. (2015). Learning by expanding. Cambridge University Press.

Engeström, Y., \& Sannino, A. (2010). Studies of expansive learning: Foundations, findings and future challenges. Educational Research Review, 5(1), 1-24.

European Commission. (2007). European competences for lifelong learning. Luxembourg: Publication Office of the European Union.

European Commission. (2014). Entrepreneurship education. A guide for teachers. Brussels: Unit entrepreneurship 2020.

European Commission. (2016). A new skills agenda for Europe. Retrieved from http://ec.europa. eu/social/main.jsp?catId=1223.

Gordon, J., Halász, G., Krawczyk, M., Leney, T., Michel, A., Pepper, D., ... Wiśniewski, J. (2009). Key competences in Europe: Opening doors for lifelong learners across the school curriculum and teacher education. In. Retrieved from http://www.case-research.eu/en/key-competences-ineurope-opening-doors-for-lifelong-learners-across-the-school-curriculum.

Haara, F. O., \& Jenssen, E. S. (2016). Pedagogical entrepreneurship in teacher education-what and why? Tímarit um uppeldi og menntun, 25(2), 183-196.

Heinonen, J., \& Poikkijoki, S.-A. (2006). An entrepreneurial-directed approach to entrepreneurship education: mission impossible? Journal of Management Development, 25(1), 80-94.

Jones, C., \& Spicer, A. (2009). Unmasking the entrepreneur: Edward Elgar.

Kolb, D. A. (1984). Experiential learning: experience as the source of learning and development Englewood Cliffs. N.J.: Prentice-Hall.

Kumpulainen, K., Kajamaa, A., \& Rajala, A. (2018). Understanding educational change: Agencystructure dynamics in a novel design and making environment. Digital Education Review(33), 26-38.

Kyro, P. (2006). Entrepreneurship education and Finnish society. Retrieved from http://www. researchgate.net/profile/Paula_Kyroe/publication/24137728_Entrepreneurship_Education_ and_Finnish_Society/links/00b7d5343b20aab43b000000.pdf. 
Lackeus, M. (2015). Entrepreneurship in Education. What, why, when, how. Retrieved from http:// www.oecd.org/cfe/leed/BGP_Entrepreneurship-in-Education.pdf.

Morselli, D. (2017). How do Italian vocational teachers educate for a sense of initiative and entrepreneurship?. Development and initial application of the SIE questionnaire: Education + Training.

Morselli, D., Costa, M., \& Margiotta, U. (2014). Entrepreneurship education based on the Change Laboratory. The International Journal of Management Education, 12, 333-348.

Peltonen, K. (2015). How can teachers' entrepreneurial competences be developed? A collaborative learning perspective. Education + Training, 57(5), 492-511.

Penaluna, K., Penaluna, A., Usei, C., \& Griffiths, D. (2015). Enterprise education needs enterprising educators: A case study on teacher training provision. Education + Training, 57(8/9), 948-963.

QAA. (2018). Enterprise and entrepreneurship education: Guidance for UK Higher Education Providers. Gloucester: Quality Assurance Agency. Retrieved from www.qaa.ac.uk.

Ravitch, S. M., \& Carl, N. M. (2015). Qualitative research: Bridging the conceptual, theoretical, and methodological. Los Angeles: SAGE Publications.

Ruskovaara, E., Hämäläinen, M., \& Pihkala, T. (2016). HEAD teachers managing entrepreneurship education-Empirical evidence from general education. Teaching and Teacher Education, 55, $155-164$.

Ruskovaara, E., \& Pihkala, T. (2015). Entrepreneurship education in schools: empirical evidence on the teacher's role. The Journal of Educational Research, 108(3), 236-249.

Sannino, A. (2016). Double stimulation in the waiting experiment with collectives: Testing a Vygotskian model of the emergence of volitional action. Integrative Psychological and Behavioral Science, 50(1), 142-173.

Sannino, A., \& Engeström, Y. (2017). Co-generation of societally impactful knowledge in Change Laboratories. Management Learning, 48(1), 80-96.

Sannino, A., Engeström, Y., \& Lemos, M. (2016). Formative interventions for expansive learning and transformative agency. Journal of the Learning Sciences, 25(4), 599-633.

Sturing, L., Biemans, H. J., Mulder, M., \& De Bruijn, E. (2011). The nature of study programmes in vocational education: evaluation of the model for comprehensive competence-based vocational education in the Netherlands. Vocations and Learning, 4(3), 191-210.

Virkkunen, J. (2006). Dilemmas in building shared transformative agency. Activités, 3(3-1).

Virkkunen, J., \& Newnham, D. S. (2013). The Change Laboratory. A tool for Collaborative Development of Work and Education. Rotterdam: Sense.

Open Access This chapter is licensed under the terms of the Creative Commons Attribution 4.0 International License (http://creativecommons.org/licenses/by/4.0/), which permits use, sharing, adaptation, distribution and reproduction in any medium or format, as long as you give appropriate credit to the original author(s) and the source, provide a link to the Creative Commons license and indicate if changes were made.

The images or other third party material in this chapter are included in the chapter's Creative Commons license, unless indicated otherwise in a credit line to the material. If material is not included in the chapter's Creative Commons license and your intended use is not permitted by statutory regulation or exceeds the permitted use, you will need to obtain permission directly from the copyright holder.

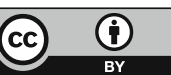

